Letter

\title{
Fluorinated thin gate oxides prepared by room temperature deposition followed by furnace oxidation
}

\author{
Kuo-Lang Yeh ${ }^{\mathrm{a}}$, Ming-Jer Jeng ${ }^{\mathrm{b}}$, Jenn-Gwo $\mathrm{Hwu}^{\mathrm{a}}{ }^{\mathrm{a}}$ * \\ ${ }^{a}$ Rm. 446, Department of Electrical Engineering, National Taiwan University, Taipei, Taiwan, ROC \\ ${ }^{\mathrm{b}}$ Department of Electronic Engineering, St. John's and St. Mary's Institute of Technology, Taipei, Taiwan, ROC
}

Received 1 December 1997; received in revised form 1 July 1998

\begin{abstract}
Room temperature deposition in $\mathrm{H}_{2} \mathrm{SiF}_{6}$ solution, i.e., liquid phase deposition (LPD), followed by furnace oxidation (FO) is first used to prepare fluorinated thin oxides (LPD/FO). The amount of fluorine existing in the gate oxide is controlled by varying the LPD time in this work. A turnaround breakdown behavior is observed for LPD/FO oxides with various LPD conditions. The oxide with an optimized fluorine concentration shows a significant improvement in oxide breakdown characteristics. (C) 1999 Elsevier Science Ltd. All rights reserved.
\end{abstract}

\section{Introduction}

A key issue of ultra-large-scale integration technology (ULSI) is the quality of thin silicon dioxide layer used in device. Today, oxide thickness less than $80 \AA$ and oxidation temperatures at about $800-900^{\circ} \mathrm{C}$ are required as the semiconductor industry pushes toward 1 Gbit memory chips and beyond. However, good electric characteristic generally needs high temperature treatment either in oxidation or in postoxidation annealing (POA). At low temperatures, ultrathin $\mathrm{SiO}_{2}$ films prepared by the conventional furnace oxidation method have some problems, such as high-density dangling bonds at the interfaces, large fixed charge density and more pinholes in the bulk. To solve these problems, the incorporation of small amounts of $\mathrm{F}$ into $\mathrm{SiO}_{2}$ was demonstrated to be efficient to improve the $\mathrm{SiO}_{2} / \mathrm{Si}$ interface hardness against hot-electron or radiation damage [1-5]. There are a number of ways to introduce fluorine into the gate oxide, including in-situ $\mathrm{NF}_{3}$ oxidation [3], diffusion with a fluorine-rich LPCVD tungsten silicide film [6], and ion implantation [4]. Recently, a room-temperature liquid

* Corresponding author. Tel.: +886-2-2363-5251-446; fax: $+886-2-2363-8247$ phase deposition (LPD) method is proposed to prepare fluorine-enriched oxides [7]. In this work, high-temperature furnace oxidation (FO) treatment to LPD fluorinated oxides is studied.

It is known that liquid phase deposition (LPD) is a room-temperature method for $\mathrm{SiO}_{2}$ formation. To date, LPD-oxide films can be deposited by adding either $\mathrm{H}_{3} \mathrm{BO}_{3}$ [8] or $\mathrm{Al}$ [7] to supersaturated hydrofluorosilicic acid $\left(\mathrm{H}_{2} \mathrm{SiF}_{6}\right)$. However, these methods suffer from the chemical contamination and make the deposition reaction in LPD complicated. In addition, the deposition rate is also too fast to grow high-density thin oxides by these ways. For this reason, the LPD method with $\mathrm{H}_{2} \mathrm{O}$ addition only is used in this work. It is known that the amount of $\mathrm{F}$ incorporated in gate oxide can be controlled by the initial LPD growth time. The following FO treatment time and temperature will also affect the $\mathrm{F}$ concentration in fluorinated oxides, since the $\mathrm{F}$ atoms introduced by LPD process can escape from fluorinated gate oxides in the form of $\mathrm{SiOF}^{+}$at a threshold temperature of $550^{\circ} \mathrm{C}$ or in the form of $\mathrm{SiF}_{3}^{+}$at a threshold temperature of $600^{\circ} \mathrm{C}$ [9]. To study the effect of fluorine on the electrical properties of thin fluorinated oxides, the LPD/FO oxides with different LPD time followed by furnace oxidation $\left(900^{\circ} \mathrm{C}\right)$ treatment are examined. It is found that the flat-band voltage $V_{\mathrm{fb}}$ and midgap interface trap density 
$D_{\text {itm }}$ for LPD/FO oxides are strongly dependent on LPD conditions. Also, it is observed that both the charge-to-breakdown, $Q_{\mathrm{BD}}$, and oxide breakdown field, $E_{\mathrm{BD}}$, characteristics of $\mathrm{LPD} / \mathrm{FO}$ samples exhibit turnaround dependency on LPD growth time. The oxide quality is controllable by adjusting the LPD time in $\mathrm{LPD} / \mathrm{FO}$ oxides.

\section{Experimental}

The experimental flowchart for preparing the immersion solution and the LPD samples is similar to the previous work [8]. Briefly, the preparation of the LPD sample needs four steps as follows. To start with, the industrial grade hydrofluorosilicic acid $\left(\mathrm{H}_{2} \mathrm{SiF}_{6}\right)$ with a concentration of $3.09 \mathrm{~mol} \mathrm{l}^{-1}$ is used. Then, the silica$x \mathrm{H}_{2} \mathrm{O}$ powder was added to consume the residual hydrofluoric acid (HF). After this, the mixed solution was filtered by a $1 \mu \mathrm{m}$ filter paper to remove the undissolved gel-formed silica powder after stirring the solution by magnetic stirrer for more than $3 \mathrm{~h}$ at $25^{\circ} \mathrm{C}$. Now, the $\mathrm{H}_{2} \mathrm{SiF}_{6}$ solution is saturated with silica and ready for oxide deposition. Before starting to deposit the LPD oxide, a certain quantity of deionized (DI) water was added to the saturated solution. The adding DI water to the saturated solution is necessary to initiate the LPD oxide deposition. It is noted that the quantity of DI water added will make influence on the deposition rate, growth delay time and electrical properties [8]. The large amount of DI water added to saturated solution will result in high deposition rate and poor oxide quality [10]. To obtain good oxide quality, a relatively low deposition rate is suggested. The volume ratio of saturated $\mathrm{H}_{2} \mathrm{SiF}_{6}$ solution to DI water is $100 \mathrm{ml}$ to $25 \mathrm{ml}$ in this work.

The MOS capacitors tested in this work are fabricated on 4 in. (100) P-type silicon substrates with a resistivity of 7-10 $\Omega \mathrm{cm}$. After standard RCA clean $\left(\mathrm{NH}_{4} \mathrm{OH}: \mathrm{H}_{2} \mathrm{O}_{2}: \mathrm{H}_{2} \mathrm{O}=0.1: 1: 5\right) \quad$ followed by $50: 1$ $\mathrm{H}_{2} \mathrm{O}: \mathrm{HF}$ dip and DI water rinse, wafers were put in the above-mentioned $\mathrm{H}_{2} \mathrm{SiF}_{6}$ solution for 10,20 , 40, and $60 \mathrm{~min}$ to deposit various LPD oxides at $25^{\circ} \mathrm{C}$ with thickness ranging from 5 to $20 \AA$. Then, the above wafers in accompany with one control sample, i.e., bare $\mathrm{Si}$ wafer, were furnace oxidized in pure dry $\mathrm{O}_{2}$ gas at $900^{\circ} \mathrm{C}$ followed by an in situ POA anneal in $\mathrm{N}_{2}$ for $10 \mathrm{~min}$. These LPD/FO samples are labeled as L10/FO, L20/FO, L40/FO, L60/FO and control.

Aluminum film is evaporated onto all samples to serve as metal gate electrodes in this work. After photolithography, back side oxides are stripped and followed by metallization. The samples employed for measurement of $C-V$ characteristics are annealed by postmetallization (PMA) in pure $\mathrm{N}_{2}$ ambient at $400^{\circ} \mathrm{C}$ for $10 \mathrm{~min}$, and those used for oxide reliability tests don't receive such PMA treatment to avoid Al penetration. The area of the MOS capacitors used for reliability characterization is $1 \times 10^{-4} \mathrm{~cm}^{2}$. The oxide film thickness is measured by ellipsometry with a fixed refractive index of 1.46. In time zero dielectric breakdown (TZDB) tests, a $0.5 \mathrm{~V} \mathrm{~s}^{-1}$ staircase ramp voltage is stressed and the oxide breakdown field is defined as the electric field at which the current density across the oxide exceeds $0.5 \mathrm{~A} \mathrm{~cm}^{-2}$. For time dependent dielectric breakdown (TDDB) tests, Fowler-Nordheim (F$\mathrm{N}$ ) injection with a constant current density of $10 \mathrm{~mA}$ $\mathrm{cm}^{-2}$ is performed on the MOS capacitors. It is noted that all reliability tests in this work are in accumulation electron injection mode, i.e., a negative gate bias for all MOS capacitors.

\section{Electrical characteristics of the LPD/FO oxides}

The initial LPD oxide properties are first examined. From SIMS profiles (not shown in this work), it is observed that longer LPD growth time introduces a larger amount of $\mathrm{F}$ incorporated in the gate oxide. It is believed that different $\mathrm{F}$ densities and distributions will result in different electrical properties. Fig. 1 shows the flat-band voltage, $V_{\mathrm{fb}}$, and the midgap interface trap density, $D_{\text {itm }}$, for the control, L10/FO, L20/ FO, and L60/FO samples. It is observed that all the $V_{\mathrm{fb}}$ and $D_{\mathrm{itm}}$ increase with LPD growth time, i.e., the number of $\mathrm{F}$ atoms incorporated in oxide changes with LPD time. It is supposed that two-step processes occur in the LPD/FO oxides during FO treatment. In the first step, the F atoms will escape from the initial LPD oxides by diffusing into and out of the gate oxide in the form of $\mathrm{SiOF}^{+}$or $\mathrm{SiF}_{3}^{+}$, which will produce a number of defects and dangling bonds in the bulk oxide [9]. Some of the $\mathrm{F}$ atoms will replace $\mathrm{Si}-\mathrm{OH}$ or $\mathrm{Si}-\mathrm{H}$ bonds by much stronger $\mathrm{Si}-\mathrm{F}$ bonds. On the

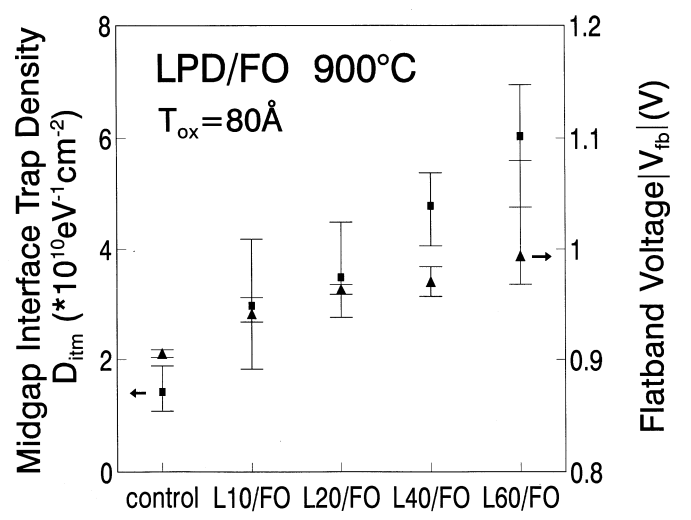

Fig. 1. The flat-band voltage $V_{\mathrm{fb}}$ and midgap interface trap density $D_{\text {itm }}$ for the control, L10/FO, L20/FO and L60/FO samples. 


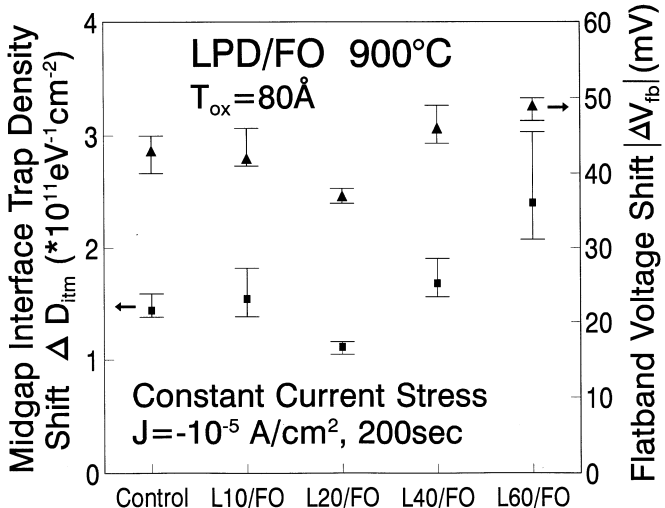

Fig. 2. The flat-band voltage shift $\Delta V_{\mathrm{fb}}$ and the midgap interface trap density shift $\Delta D_{\text {itm }}$ after constant current stress for various $\mathrm{LPD} / \mathrm{FO}$ oxides.

other hand, the decomposition of $\mathrm{Si}-\mathrm{OH}$ bonds existing in LPD oxides will lead to the existence of $\mathrm{H}^{+}$or oxygen vacancies $\mathrm{O}_{3}=\mathrm{Si} \cdot \mathrm{Si}=\mathrm{O}_{3}$ in the oxide film at the same time [11]. It results in the increase of $D_{\text {itm }}$ and positive charges at $\mathrm{Si} / \mathrm{SiO}_{2}$ interface, which makes the left shift in the $C-V$ curves for all LPD/FO samples. Consequently, in this step, it possibly induces higher interface trap density from oxygen vacancies and more disordered fixed charge $Q_{\mathrm{f}}$ distribution at the interface. In the second step, these produced defects and oxygen vacancies will be passivated by oxygen atoms to form $\mathrm{Si}-\mathrm{O}$ bonds. This effect will result in the reduction of the defects and positive charges. However, not all of the defects and oxygen vacancies can be passivated in this step. It depends on the initial LPD growth time and the following treatment time and temperature. By this two step mechanism, the trends in $V_{\mathrm{fb}}$ and $D_{\mathrm{itm}}$ can be explained. When the LPD oxide fraction is small, i.e., the LPD oxide growth time shorter than 20 min, the defects are not so much that the oxygen can restructure these dangling bonds. Hence, the variation of $V_{\mathrm{fb}}$ and $D_{\mathrm{itm}}$ are similar to the control oxide for LPD/FO oxides with small LPD fractions. As the fraction of LPD oxide increases, the dangling bonds will become too many to be passivated by oxygen and the shifts in $V_{\mathrm{fb}}$ and $D_{\mathrm{itm}}$ become large.

However, it has been reported that incorporating $\mathrm{F}$ into oxides with implantation $[12,4]$ or in-situ oxidation [13] method can reduce $D_{\text {itm. }}$. This is contrary to the observation of this work. The possible reason is that the LPD oxides may decompose into $\mathrm{Si}-$ $\mathrm{OH}$. This decomposition introduces the oxygen vacancies which are the precursors of interface states [14]. The $\mathrm{H}^{+}$release will induce some positive charges in oxides. Thus, it will result in large $D_{\text {itm }}$ and $V_{\mathrm{fb}}$ in LPD/FO oxides. In addition, it is supposed that the high-temperature process $\left(\sim 900^{\circ} \mathrm{C}\right)$ may be another reason for the anomalous effect observed in this work since it makes more $\mathrm{F}$ evaporate and leaves less $\mathrm{Si}-\mathrm{F}$ bonds in the interface.

The effect of $F$ fraction on the resistance to hot-electron damage is examined by a constant FowlerNordheim current stress with a current density of 10 $\mu \mathrm{A} \mathrm{cm}{ }^{-2}$ for 200 s, i.e., a total charge of $0.2 \mathrm{mC} \mathrm{cm}^{-2}$, under gate injection $\left(-V_{\mathrm{g}}\right)$. In Fig. 2, the changes of flat-band voltage $\Delta V_{\mathrm{fb}}$ and midgap interface trap den-

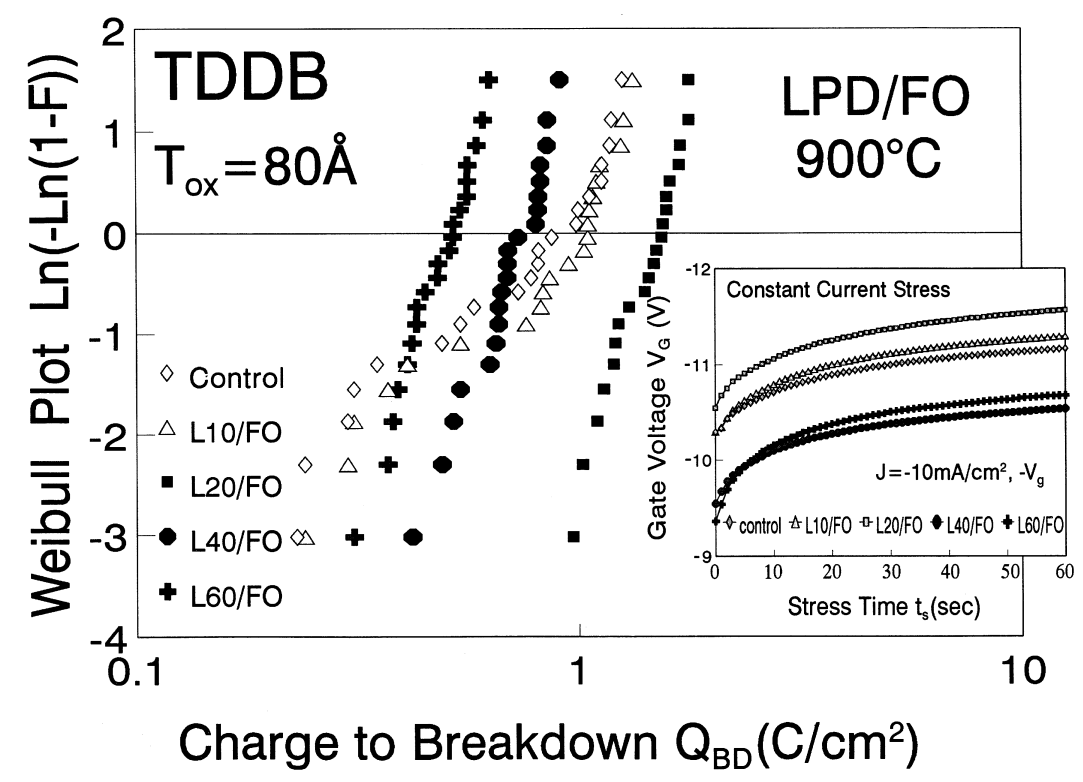

Fig. 3. Weibull plots of charge-to-breakdown $Q_{\mathrm{BD}}$ for various $\mathrm{LPD} / \mathrm{FO}$ oxides. The inset is gate voltage versus stress time for various $\mathrm{LPD} / \mathrm{FO}$ oxides during constant current stress. 


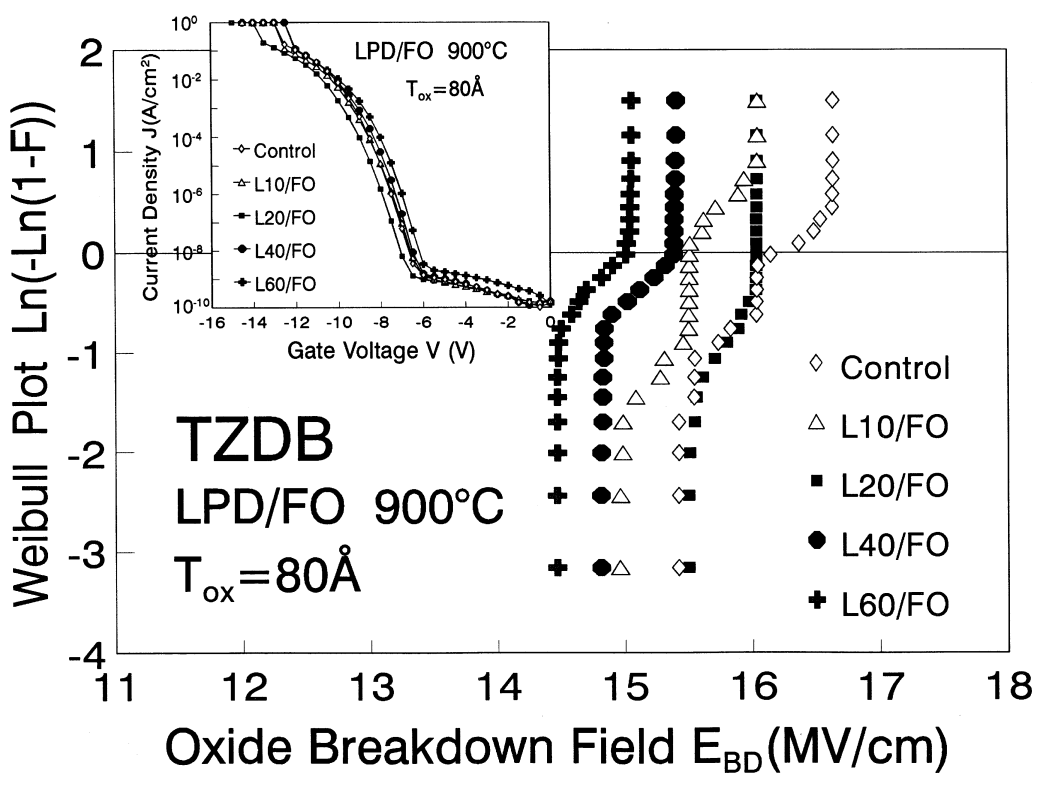

Fig. 4. Weibull plots of oxide breakdown field $E_{\mathrm{BD}}$ for various LPD/FO oxides. The corresponding $J-V$ characteristics are shown in the inset.

sity $\Delta D_{\text {itm }}$ after stressing are plotted for various LPD/ FO oxides. It is found that the $\Delta V_{\mathrm{fb}}$ and $\Delta D_{\mathrm{itm}}$ for the LPD/FO oxides with high fluorine content are seriously degraded. However, it is worth noticing that for the sample with a suitable LPD condition, i.e., the L20/FO sample, there exists a higher resistance to hotelectron injection than control one. It is known that the amount of $\mathrm{F}$ incorporated into $\mathrm{SiO}_{2}$ should play an important role in determining the resistance of the $\mathrm{SiO}_{2} / \mathrm{Si}$ interface against hot-carrier damage. As $\mathrm{F}$ exists in the oxide, it will improve the interface because of strain relaxation and replacing $\mathrm{Si}-\mathrm{H}$ bonds by the much stronger $\mathrm{Si}-\mathrm{F}$ bonds. However, if the interface regions have been saturated with fluorine, the additional incorporation of $\mathrm{F}$ will be harmful to oxides. The extra $\mathrm{F}$ atoms in the bulk may cleave the $\mathrm{Si}-\mathrm{O}$ bonds and displace oxygen at these sites $[12,13]$. It is speculated that these interfacial nonbridging oxygen centers, after giving up an electron to Si by the displacement of F, may be a candidate for positive fixed charge. This step increases and redistributes the bulk fixed charges for all LPD/FO oxides more or less. The negative flat-band shift for all $\mathrm{LPD} / \mathrm{FO}$ oxides is also explainable by this way.

Fig. 3 show the Weibull plots of the $Q_{\mathrm{BD}}$ for various LPD/FO oxides with a similar final oxide thickness of $80 \AA$. It is observed that the $Q_{\mathrm{BD}}$ 's exhibit turnaround dependency on LPD growth time. The L20/FO sample exhibits a higher $Q_{\mathrm{BD}}$ than the control oxide. It has been reported that charge trapping and trap generation are the key processes in dielectric breakdown [15-19].
Because of the large stress at the $\mathrm{Si} / \mathrm{SiO}_{2}$ interface, the strained interface is inherently weaker than the bulk oxide and the trapping is believed to be more severe at the interface $[16,17,20-22]$. In order to examine the generation of new oxide traps under high-field hotelectron injection, the gate voltage versus stress time during a constant Fowler-Nordheim current stressing is also shown in the inset of Fig. 3 for comparison. The electron trapping behavior is observed due to negative electric filed shift. A non-linear electric field increases due to the charging of initial traps [23]. From the inset, it indicates that the voltage shift of the low fraction LPD/FO oxide is similar to that of the high fraction one but only a little larger than the control oxide. It is known that a non-saturating quasi-linear electric field increases corresponding to the generation of new electron traps and their partial occupation [17]. Although the LPD/FO oxides exhibit more electron traps, their inclinations to the generation of new oxide traps are nearly identical to the control oxide except for the highest fraction LPD/FO one. Furthermore, it is worth noticing that the LPD/FO oxides sustain lower electric field for constant current stress than control oxide does, which implies that the LPD/FO oxide exists larger leakage current than control oxide. The Weibull plots of the $E_{\mathrm{BD}}$ for various $\mathrm{LPD} / \mathrm{FO}$ oxides are shown in Fig. 4. It is noted that the $E_{\mathrm{BD}}$ of control oxide is larger than all LPD/FO oxides. The typical $J$ $V$ characteristics of the LPD/FO and control oxides are also shown in the inset of Fig. 4 for comparison. It is observed that the leakage currents of LPD/FO ox- 
ides are larger than that of control one. It is believed that they are strongly related to the fraction of $F$.

\section{Discussion}

There are numerous models regarding the breakdown mechanism, including the so-called hole-induced breakdown model [24-27], the electron-trapping breakdown model [17], the interface-trap generation and resonant-tunneling-induced breakdown models [28] as well as the anode hole injection breakdown model [2935]. Although there is no strong consensus concerning the breakdown mechanism, it is generally accepted that the breakdown is a two step process, i.e., wearout followed by breakdown. Wearout is caused by trap generation inside the oxide. Breakdown is induced by local high current regions, which are triggered by a local increase in the current density. In other words, the occurrence of TDDB mainly relies on the distribution and generation of oxide trap number density $N_{\text {ot }}$ but not on the initial effective oxide charges.

For constant current TDDB test of LPD/FO oxides, two major factors compete with each other as the LPD oxide fraction increases. One is the addition of induced electron traps and defects, and the other is the enhancement of the existence of $\mathrm{Si}-\mathrm{F}$ bonds. The former causes larger a electric field in the interface and the latter intensifies the endurance to the impact ionization. As a result, the turnaround behavior of $Q_{\mathrm{BD}}$ is observed. It means that the reliability of the LPD/FO oxides is strongly dependent on the fraction of LPD oxides. Since the $\mathrm{F}$ can replace $\mathrm{Si}-\mathrm{H}$ or $\mathrm{Si}-\mathrm{OH}$ and compensate dangling bonds in the form of stronger $\mathrm{Si}-$ $\mathrm{F}$ bonds, some LPD/FO oxides have higher reliability than control ones. For the TZDB test of LPD/FO oxides, there are also two major factors competing with each other as the LPD oxide fraction increases. One is the addition of induced electron traps and the other is the increase of the disorder of the fixed charge distribution. Between these two factors, the former leads to larger $E_{\mathrm{BD}}$ and the latter causes the localized higher field to lower the $E_{\mathrm{BD}}$. For this reason, the turnaround behavior will occur. It emphasizes again that there is a strong relation between the reliability and the fraction of initial LPD oxides for LPD/FO samples.

\section{Conclusion}

In this work, the fraction effect of $F$ atoms in LPD/ FO oxides by varying the initial LPD time has been studied. The most suitable $\mathrm{F}$ fraction for preparing 80 $\AA$ oxides at $900^{\circ} \mathrm{C}$ in this work is $\mathrm{L} 20 / \mathrm{FO}$, which gets a larger $Q_{\mathrm{BD}}$ and a higher resistance to hot-electron than control one. However, a turnaround breakdown behavior exists in LPD/FO oxides. Too long LPD growth time will degrade the quality of the oxides in all aspects, possibly due to the too much left oxygen vacancies from the evaporation of $\mathrm{F}$ and decomposition of $\mathrm{Si}-\mathrm{OH}$ bonds. Nevertheless, the room temperature LPD followed by FO provides a new method to prepare thin fluorinated gate oxides. The controllability of $\mathrm{F}$ content in LPD/FO oxides by adjusting LPD time is attractive and is worthy of studying in the near future.

\section{Acknowledgements}

The authors want to thank the National Science Council of the Republic of China for supporting this work under Contract No. NSC86-2215-E-002-020.

\section{References}

[1] Vishnubhotla L, Ma TP, Tseng H-H, Tobin PJ. Appl Phys Lett 1991;59(27):3595.

[2] Wright PJ, Saraswat KC. IEEE Trans Electron Devices 1989;36:879.

[3] Huang JG, Jaccodine RJ. J Electrochem Soc 1993; 140:L15.

[4] Nishioka Y, Ohyu K, Ohji Y, Natuaki N, Mukai K, Ma T-P. IEEE Electron Device Lett 1989;10:141.

[5] Wright PJ, Kasai N, Inoue S, Sarawat KC. IEEE Electron Device Letters 1989;10:347.

[6] Shioya Y, Kawamura S, Kobayashi I, Maeda M, Yanagida K. J Appl Phys 1987;58:5102.

[7] Yeh CF, Lin SS, Yang TZ, Chen CL, Yang YC. IEEE Trans Electron Devices 1994;41:173.

[8] Lu WS. PhD Dissertation, Department of Electrical Engineering, NTU, chap 3-4, 1995.

[9] Jeng SP, Ma TP, Canteri R, Anderle M, Rubloff GW. Appl Phys Lett 1992;61:1310.

[10] Yeh CF, Chen CL, Lin GH. J Electrochem Soc 1994; 141:3177.

[11] Fan CH, Master Thesis, Department of Electronic Engineering, NCTU, chap 2, 1996.

[12] Kouvatsos DN, Stevie FA, Jaccodine RJ. J Electrochem Soc 1993; 140:1160.

[13] Ahn J, Lo GQ, Ting W, Kwong DL, Kuehne J, Magee CW. Appl Phys Lett 1991;58:425.

[14] Lo GQ, Kwong DL, Abbott KJ, Nazarian D. J Electrochem Soc 1993;140:L16.

[15] Chen IC, Holland S, Hu C. IEEE Trans Electron Devices 1985;32:413.

[16] DiMaria DJ, Cartier E, Arnold D. J Appl Phys 1993; $73: 3367$.

[17] Harari E. J Appl Phys 1978;49:2478.

[18] Anvi E, Shappir J. J Appl Phys 1988;64:743.

[19] DiMaria DJ, Stasiak JW. J Appl Phys 1989;65:2342.

[20] Horiguchi S, Kobayashi T. IEEE Trans Electron Devices 1994;41:1595.

[21] Lai SK. J Appl Phys 1983;54:2540. 
[22] Nissan-Cohen Y, Shappir J, Frohman-Bentchkowsky D. J Appl Phys 1986;60:2024.

[23] Lee JC, Chen I-C, Hu C. IEEE Trans Electron Devices 1985;32:413.

[24] Shatzkes M, Av-Ron M. J Appl Phys 1976;47:3192.

[25] Kashat I, Klein N. J Appl Phys 1977;48:5217.

[26] Chen IC, Holland S, Hu C. IEEE Electron Device Lett 1986;7:164.

[27] Ricco B, Azbel M, Brodsky M. Phys Rev Lett 1983;51:1795.

[28] Fonseca L, Campabadal F. IEEE Electron Device Lett 1994;15:449.
[29] Gao X, Yee SS. J Appl Phys 1994:76(10):5795.

[30] DiMaria DJ, Cartier E, Buchanan DA. J Appl Phys 1996;80(1):304.

[31] DiMaria DJ. IEEE Electron Device Lett 1995;16:184.

[32] DiMaria DJ, Cartier E. J Appl Phys 1995;78:3883.

[33] Satake H, Yasuda N, Takagi SI, Toriumi A. Appl Phys Lett 1996;69:1128.

[34] Depas M, Nigam T, Heyns MM. IEEE Trans Electron Devices 1996;43:1499.

[35] Dumin DJ, Maddux JR, Scott RS, Subramoniam R. IEEE Trans Electron Devices 1994;41:1570. 